\title{
Correction to: Psychometric Performance of the Miller Forensic Assessment of Symptoms Test (M-FAST) in Veteran PTSD Assessment
}

\author{
Erika J. Wolf ${ }^{1,2} \cdot$ Stephanie Ellickson-Larew ${ }^{1} \cdot$ Rachel E. Guetta $^{1,3} \cdot$ Shaline Escarfulleri ${ }^{1} \cdot$ Karen Ryabchenko $^{1,2}$. \\ Mark W. Miller ${ }^{1,2}$
}

Published online: 2 September 2020

(C) Springer Science+Business Media, LLC, part of Springer Nature 2020

Correction to: Psychological Injury and Law https://doi.org/10.1007/s12207-020-09373-y

Correction of mistake in the original version of this paper, "Psychometric Performance of the Miller Forensic Assessment of Symptoms Test (M-FAST) in Veteran PTSD Assessment", specifically, in Table 2, the cell for item 13 under the "testing the limits" header should read " 0.0 " and not " 15.8 ".

Publisher's Note Springer Nature remains neutral with regard to jurisdictional claims in published maps and institutional affiliations.

The online version of the original article can be found at https://oi.org/ 10.1007/s12207-020-09373-y

Erika J. Wolf

erika.wolf@va.gov

1 National Center for PTSD at, VA Boston Healthcare System, $150 \mathrm{~S}$. Huntington Ave. (116B-2), Boston, MA, USA

2 Department of Psychiatry, Boston University School of Medicine, Boston, MA, USA

3 Department of Psychology and Neuroscience, Duke University, Durham, NC, USA 